\title{
Endoscopic Diathermy-assisted DCR: A New Concept
}

\author{
Shubhrica, Rupender K Ranga
}

\begin{abstract}
Endoscopic diathermy-assisted technique is very safe, quick, less traumatic, with minimal blood loss, less tissue scarring and less postoperative discomfort and last but not the least, the ease of creating big size ostium. It has high success rate in both primary and secondary cases. Fifty-four cases of chronic dacryocystitis were treated by the endoscopic diathermy technique including 42 females and 12 males with mean age 34.66 years, 38 left eye and 16 right eye. Four patients were cannulated with nasolacrimal tube with very good results and few complications.
\end{abstract}

Keywords: Endoscopic diathermy dacryocystorhinostomy, External dacryocystorhinostomy, Chronic dacryocystitis.

How to cite this article: Shubhrica, Ranga RK. Endoscopic Diathermy-assisted DCR: A New Concept. Clin Rhinol An Int J 2013;6(2):88-91.

Source of support: Nil

Conflict of interest: None declared

\section{INTRODUCTION}

Dacryocystorhinostomy (DCR) is a surgical procedure by which lacrimal flow is diverted into nasal cavity through an artificial opening made at level of lacrimal sac. However, endoscopic endonasal dacryocystorhinostomy (Endo-DCR) is gaining popularity as the procedure leaves no external facial scar and it can be performed even in cases of lacrimal abscess. ${ }^{1}$ It is an alternative approach to conventional external DCR, because of close anatomical relationship of lacrimal sac and lateral wall of nasal cavity. ${ }^{2}$ The most common cause of blockage of neo-ostium is granulation tissue or synechia that develop in postoperatively period. It may be due to inadequate exposure of lacrimal sac, consequent to limited resection of bone and unnecessary removal or injury of surrounding nasal and lacrimal sac mucosa.

Historically, the majority of surgery for nasolacrimal duct with obstruction has been performed through external technique with excellent results and is supposed to be gold standard, however, conventional DCR has several disadvantages like cutaneous scar formation, potential injury to adjacent medial canthal structure (medial canthal tendon), immediate postoperative morbidity (periorbital ecchymosis and epistaxis) and delayed postoperative morbidity, i.e. intranasal scarring with obstruction of DCR and/or sinus ostia leading onto recurrent lacrimal obstruction or sinusitis or both. ${ }^{3,4}$ The search for an alternative to external approach is motivated by the desire to improve DCR success rates with better cosmetic results. Review of literature validate that success rate of endoscopic DCR are comparable with external technique. Although, several methods for excision of medial wall of lacrimal sac have been described in literature like cold instruments, laser and powered instruments. The main objective of this study was to create neo-ostium with transcanalicular diathermy and evaluation of patency in chronic dacryocystitis.

\section{MATERIALS AND METHODS}

A prospective study was conducted in 54 cases of chronic dacryocystitis in age group of 18 to 52 years which were referred by eye surgeons. Endoscopic transcanalicular diathermy DCR was performed in patients of nasolacrimal duct blockage, who were refractory to conservative medical treatment. A detailed history was taken about persistent watering and recurrent mucopurulent discharge, recurrent pain in medial aspect of eye and swelling over lacrimal sac area, congestion of eye ball, regurgitation on pressure over sac area and facial trauma. General physical, eye and ENT examination was carried out to arrive at diagnosis of nasolacrimal pathway obstruction. Systemic disorders like hypertension, tuberculosis and diabetes were ruled out. The diseases which are known to cause lacrimal system blockage like lacrimal sac malignancy, severe bony deformity of lacrimal fossa (post-traumatic), acute infections of conjunctiva and sac and lacrimal sac tuberculosis were excluded from the study. Diagnosis was confirmed after syringing and irrigation of lacrimal canaliculi with a 23/26 G lacrimal cannula.

\section{Operative Technique}

In all patients endoscopic diathermy-assisted DCR, was performed using 300 Hopkins rigid endoscope under local anesthesia after premedication with pethidine $50 \mathrm{mg}$ and phenergan $25 \mathrm{mg}$ intramuscularly half an hour prior to surgery. General anesthesia was given in four patients. Nasal cavity was anesthetized with cotton soaked in $4 \%$ lignocaine with xylometazoline HCL $0.1 \%$ for about 15 to 20 minutes. This gave easy access, mucosal anesthesia and comparatively bloodless field. The patient was made to lie down in supine position with head end elevated by 10 to $15^{\circ}$ to reduce the venous pressure. External aspect of nose was cleaned with full concentration (5\%) povidone-iodine solution and 1:10 dilution of the same solution was instilled in the eye (two drops every minute for 5 minutes). Head was tilted toward the surgeon. 
Under direct endoscopic vision the anterior end of middle turbinate and the area of lateral nasal wall just anterior and superior to it was infiltrated with $2 \%$ xylocaine solution with adrenaline $(1: 30,000)$ submucosally till blanching of the area occurred. Incision in mucosa of the wall just anterosuperior to anterior attachment of middle turbinate on lateral wall was made with sickle knife and carried down to the bone, in U-shape manner and piece of mucosa $1 \times 1.5 \mathrm{~cm}^{2}$ was removed, thus the frontal process of maxilla was exposed. The junction between lacrimal bone and crest was identified. Lacrimal bone was punched with Kerrison's punch and drilled if required to expose the medial wall of lacrimal sac which was widely exposed.

Topical 4\% lignocaine drops was instilled in the eye. Lower punctum was dilated with the help of punctum dilator and a lacrimal probe was passed through the lower punctum into the sac directed medially into obstructed lacrimal sac, which made a tent on the lateral nasal wall. The transcanalicular diathermy for removal of medial wall was used in which lacrimal stent probe covered with I/V cannula of no. $22 \mathrm{G} \times 1 / 0.8 \times 2 \mathrm{~mm}$ was used (Fig. 1). After tenting of sac diathermy was fired and sac opened and widened about $1.5 \mathrm{~cm}$ and same was repeated through superior canaliculus (Fig. 2). Syringing was done on the table using normal saline fortified with amikacin solution ( $500 \mathrm{mg}$ in $20 \mathrm{ml}$ ), to confirm the patency. In four failed cases a silastic tube was put into upper and lower canaliculi into nasal cavity and was tied in fashion of multiple knots. The operated nasal cavity was filed with medicated pack which was removed after 24 hours. Postoperatively, patients were instructed to put amikacin eye drops to facilitate drainage. The nasal cavity was examined and cleaned off crusts if any. Nasal irrigation with saline was started on the next day. Patients were asked not to blow their nose for 4 to 5 days after the surgery. Postoperative evaluation was done at 2 weeks, 1, 2, 4 and 6 months after the surgery and on each

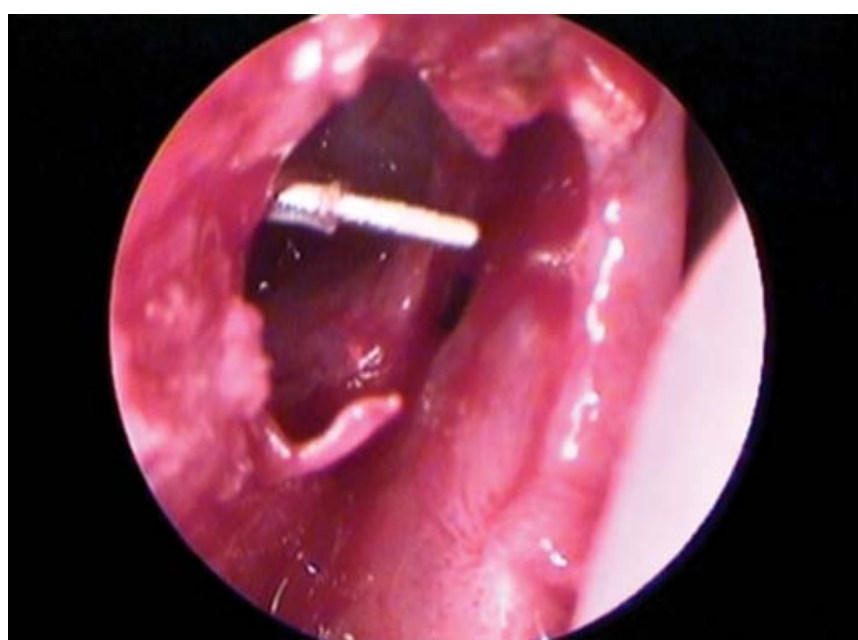

Fig. 2: Neo-ostium with insulated probe in situ

visit syringing with antibiotic and cleaning of nasal cavity for any crusts was done.

\section{OBSERVATIONS}

Out of 54 patients, there were 38 females and 16 males. The mean age was 34.66 (range: 18-52 years). Mean duration of epiphora was 1.6 year ( 2 months to 6 years), 42 being on left and 12 on right side. The silicone stent (silastic tube) was placed in four patients and kept in situ for 2 months. In all patients postoperatively endoscopic examination of wide neo-ostium and syringing revealed patient DCR except one who had a lower canaliculi blockage where upper canaliculi was cannulated with lacrimal cannula for 3 months and epiphora cleared. Three cases developed ecchymosis which subsided after 10 days. In addition to DCR, septoplasty was performed in four cases and in two cases concha bullosa wall resected (Table 1).

\begin{tabular}{lcccc}
\multicolumn{5}{c}{ Table 1: Age distribution of cases } \\
Age & $10-20$ & $20-30$ & $40-50$ & $>50$ \\
\hline No. of cases & 10 & 17 & 14 & 13 \\
$\%$ & 5.4 & 9.8 & 7.56 & 7.02 \\
\hline
\end{tabular}
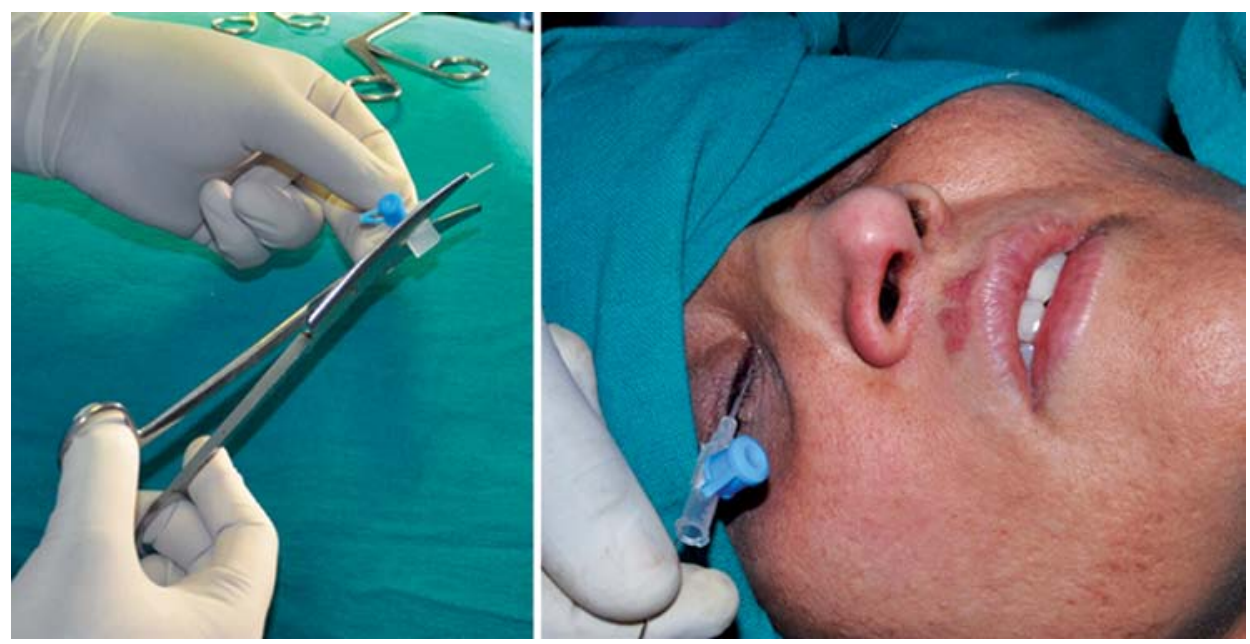

Fig. 1: I/V cannula no. 22G with metallic probe 


\section{DISCUSSION}

Since Toti described the initial DCR operation in 1904, many technical modifications have evolved. DCR consists of making a passage between lacrimal sac and middle meatus of the nose, to re-establish tear flow from sac to nasal cavity. Caldwell described the endonasal DCR in which a portion of inferior turbinate was removed and nasolacrimal canal was followed to lacrimal sac. ${ }^{5}$ Endoscopic endonasal DCR was first reported by Rice (1990) in cadavers. ${ }^{6}$ MacDonagh and Meiring (1989) studied anatomical relationship of lacrimal sac and nasolacrimal duct to lateral wall of nose. ${ }^{2}$ They also described the relation of superior border of lacrimal sac above the middle turbinate, anterior attachment lateral to agar nasi cells. There are many causes of nasolacrimal duct system blockage like chronic dacryocystitis, lacrimal abscess, mucocele and failed external DCR. ${ }^{7,8}$

The success rate of external DCR has been reported at 90 to $97 \%$ depending upon the surgeon's experience. ${ }^{1}$ Many workers conducted studies on endo-DCR with different success rates which ranged from 82 to $86 \% .{ }^{9}$ Our success rate of Endo-DCR was $98 \%$ although it is a small study. Some workers also published the study on success rate of Endo-DCR in failed external DCR and used YAG laser in Endo-DCR and reported superior results. ${ }^{10}$ It is much better in revision cases, however, it is a very costly technology.

Endo-DCR is known for many advantages like safety, ease of performance, economy, no facial scar, no injury to medial canthal tendon, no periorbital ecchymosis and no epistaxis. ${ }^{11}$ Postoperative care like meticulous clearing of the debris and early repeated irrigation with sodium bicarbonate is mandatory for good results.

There is lots of advancement in opening the medial wall of lacrimal sac in last decade. Initially it was assumed that just give two parallel incisions by cold knife in sac will be sufficient for creating passage, however, chances of fibrosis and restenosis of lacrimal passage is there. Mickelson et $\mathrm{al}^{14}$ reported that laser-assisted DCR is effective for opening the sac into the nose. The main demerit of this technique is that it is very costly. Wormald described the power endoscopic technique which confirmed the benefit and efficacy of their technique. Important tenets of this technique are wide exposure of lacrimal sac via powered removal of frontal process of maxilla and the creation and preservation of mucosal flaps to aid in long-term patency of ostium. The cost factor is still there although it is less than laser. However, we have used transcanalicular diathermy for removal of medial wall, which is very simple instrument in which lacrimal stent probe guarded with I/V cannula is used. It is very useful for creating wide neo-ostium with less intraoperative bleeding and less scarring. Further it can be used on cutting and coagulation mode in same sitting.
The main problems of endonasal DCR are doubts about long term patency and neo-ostium closure by granulation tissue and fibrosis. Antimetabolic agents like 5-FU and mitomycin $\mathrm{C}$ are known to inhibit human Tenon's capsule fibroblast proliferation by inhibiting DNA-dependent RNA synthesis, hence a single intraoperative application of 5-FU and mitomycin $\mathrm{C}$ has been used with good outcome, ${ }^{15}$ however, we did not use 5-FU in any case.

The results of Endo-DCR reflect the effect of a learning curve associated with the introduction of a new procedure, hence there is difference in the success rate of earlier studies as compared to latter one. In patients with failed Endo-DCR, a revision Endo-DCR can be done by just removal of fibrotic tissue from operated area. In our study only one case who complained of recurrent discharge postoperatively was also cured after cannulation of upper canaliculus. There was no evidence of granulation and fibrotic tissue at area of neoostium in our study.

External DCR has a failure rate ranging from 3 to $15 \%$ and revision surgery has a very poor success rate, however, in revision cases the dilemma of external incision to recreate lacrimal drainage through an already scared surgical field will be successful and is still debatable. ${ }^{16}$ Revision EndoDCR was found to have good success rate in literature. ${ }^{12,13}$ Weidenbecher reported $82 \%$ and Metson reported a $100 \%$ success rate following Endo-DCR. ${ }^{17}$

There are many advantages of Endo-DCR, but certain limitations like the need of sophisticated equipment including endoscopes and sometimes intraoperative intranasal bleeding demands more skill. Hence, this procedure should be attempted only by those with extensive experience with endoscopic nasal surgeries. ${ }^{11}$ Minor reported complications include injury to anterior nares by the drill shaft, synechia formation and ecchymosis of eye.

\section{REFERENCES}

1. David S, Raju R, Job A, Richard J. A comparative study of external and endoscopic endonasal dacryocystorhinostomy--a preliminary report. Indian J Otolaryngol Head Neck Surg 1999 Dec;52(1):37-39.

2. McDonagh M, Meiring JH. Endoscopic transnasal dacryocystorhinostomy. J Laryngol Otol 1989 Jun;103(6):585587.

3. Yung MW, Hardman-Lea S. Analysis of the results of surgical endoscopic dacryocystorhinostomy: effect of level of obstruction. Br J Opthalmol 2002 Jul;86(7):792-794.

4. Metson R. The endoscopic approach for revision dacryocystorhinostomy. Laryngoscope 1990 Dec;100(12):13441347.

5. Shunshin A, Thurairajan G. External dacryocystorhinostomy--an end of an era? Br J Ophthalmol 1997 Sep;81(9):716-717.

6. Jin HR, Yeon JY, Choi MY. Endoscopic dacryocystorhinostomy: creation of a large marsupialised lacrimal sac. J Korean Med Sci 2006 Aug;21(4):719-723. 
7. Wormald PJ. Powered endoscopic dacryocystorhinostomy. Laryngoscope 2002 Jan;112(1):69-72.

8. Toti A. Nuovo metodo conservatore di cura radicale delle suporazioni croniche del sacco lacrimale. Clin Med Firenze 1904; 10:385-389.

9. Caldwell GW. Two new operations for obstruction of nasal duct with preservation of canaliculi and an incidental description of a new lacrimal probe. NY Med J 1893;57:581-582.

10. Rice DH. Endoscopic intranasal dacryocystorhinostomy results in four patients. Arch Otolaryngol Head Neck Sur 1990 Sep;116(9):1061.

11. Ranga RK, Yadav SPS, Advin. Endo-DCR: is it an end of the road for external DCR? J Indian Med Assoc 2008 Apr;106(4):228-231.

12. Jokinen K, Karja J. Endonasal dacryocystorhinostomy. Arch Otolaryngol $1974 \mathrm{Jul} ; 100(1): 41-44$.

13. Sadiq SA, Hugkulstone CE, Jones NS, Downes RN. Endoscopic holmium: YAG laser dacryocystorhinostomy. Eye 1996;10(Pt 1):43-46.

14. Mickelson SA, Kim DK, Stein IM. Endoscopic laser assisted dacryocystorhinostomy. Am J Otolaryngol 1997 MarApr;18(2):107-111.
15. Mudhol RR, Zingade ND, Mudhol RS, Das A. Endoscopic ostium assessment following endonasal dacryocystorhinostomy with mitomycin C application. Al Ameen Med Sci 2012 Jul;5(3):320-324.

16. Tsirbas A, Davis G, Wormald PJ. Revision dacryocystorhinostomy: a comparison of endoscopic and external techniques. Am J Rhinol 2005 May-Jun;19(3):322-325.

17. Weidenbecher M, Hosemann W, Buhr W. Endoscopic endonasal dacryocystorhinostomy: results in 56 patients. Ann Otol Rhinol Laryngol 1994 May;103(5 Pt 1):363-367.

\section{ABOUT THE AUTHORS}

\section{Shubhrica}

Resident, Department of Ophthalmology, Pt BD Sharma PGIMS Rohtak, Haryana, India

\section{Rupender K Ranga (Corresponding Author)}

Director, Department of Otorhinolaryngology, Bharat ENT and Endoscopy Hospital, Rohtak Gate, Bhiwani -127021, Haryana, India e-mail: rupenderent@yahoo.co.in, bharatentbwn@sify.com 